\title{
Studies on Mass Attenuation Coefficient, Effective Atomic Numbers and Electron Densities of Some Narcotic Drugs in the Energy Range 1KeV -100GeV
}

\author{
Shivraj G. Gounhalli ${ }^{1}$, Anil Shantappa ${ }^{2}$, S. M. Hanagodimath3 \\ ${ }^{1,2,3}$ Department of Physics, Gulbarga University Gulbarga 585106, Karnataka, India
}

\begin{abstract}
The effective atomic numbers and electron densities of few narcotic drugs (ND) viz., Heroin $(H)$, Cocaine (CO), Caffeine (CA), Tetrahydrocannabinol (THC), Cannabinol (CBD), Tetrahydrocannabivarin $(T H C V)$ have been calculated for total and partial photon interactions by the direct method in the wide energy range of $1 \mathrm{KeV}-100 \mathrm{GeV}$ using WinXCOM. The values of these parameters have been found to change with energy and composition of the narcotic drugs $(N D)$. The variations of effective atomic number and electron density with energy are shown graphically for all photon interactions. The variation of photon mass attenuation coefficients with energy are shown graphically only for total photon interaction. The variation of effective atomic number $Z_{\text {eff }}$ and electron densities $N_{e l}$ is due to the variations in the dominance of different interaction processes in that particular energy region.
\end{abstract}

Keywords: Photon mass attenuation coefficients, Effective atomic numbers, Electron densities.

\section{Introduction}

With the extensive use of gamma-active isotopes in medicine, industry and agriculture, the study of absorption of gamma rays in the composite materials has become an interesting and exciting field of research. The photon mass attenuation coefficient, effective atomic number and electron density are the basic quantities required in determining the penetration of X-rays and gamma photons in matter.

The mass attenuation coefficient $(\mu / \rho)$ is a measure of probability of interaction that occurs between incident photons and matter per unit mass per unit area. The knowledge of mass attenuation coefficients of Xrays and gamma photons in biological, chemical and other important materials is of significant practical interest for industrial, biological, agricultural, defence and medical applications [1]. Accurate values of photon mass attenuation coefficients are required to provide essential data in diverse fields such as nuclear diagnostics (computerized tomography), nuclear medicine, radiation protection, radiation dosimetry, gamma ray fluorescence studies, radiation physics, shielding, security screening and etc. The mass attenuation coefficients are widely used in the calculation of photon penetration and energy deposition in shielding, biological and other dosimetric materials.

G. J. Hine [2] has pointed out that in composite materials, for photon interactions, a single number cannot represent the atomic number uniquely across the entire energy region, as in the case of pure elements. This number for composite materials is known as "effective atomic number" $\left(Z_{\text {eff }}\right)$ and it varies with energy. The energy absorption in a given medium can be calculated if certain constants are known. These necessary constants are $Z_{\text {eff }}$ and electron density $\mathrm{N}_{\mathrm{el}}$ of the medium. As effective atomic numbers and electron densities are useful in many technological applications, several investigators [3-19] have made extensive studies of effective atomic numbers in variety of composite materials like alloys, polymers, compounds, and mixtures, thermoluminescent dosimetric compounds, semiconductors and superconductors. In the past Hiremath and Chikkur (20) Manjunathaguru and Umesh (21) Manohara et al. (31) recently Pravina Pawar and Govind Bichile (22) have reported effective atomic numbers for some chemical compounds containing $\mathrm{H}, \mathrm{C}, \mathrm{O}$ and $\mathrm{N}$ atoms.

In view of the extensive use of radiative sources in medicine, agriculture, industry, security screening etc., the study of photon-atom interactions (attenuation and energy absorption coefficients) and effective atomic numbers in different materials have gained importance in the recent years.

The effective atomic number $Z_{\text {eff }}$ has an interesting application. It can be used in security screening of air passenger luggage for, in particular for low crystalline substance (23). There are almost no reports on the effective atomic number and electron density studies in literature on narcotic drugs. This prompted us to study the mass attenuation coefficient $(\mu / \rho)$ and hence effective atomic number $Z_{\text {eff }}$ and electron density $\mathrm{N}_{\mathrm{el}}$ of narcotic drugs. In this paper we report the effective atomic number and electron densities of narcotic drugs calculated by using WinXcom program in the energy region $1 \mathrm{KeV}-100 \mathrm{GeV}$.

The narcotic drugs listed in table.1 are addictive in nature to human body which harms the brain, heart, kidneys, blood vessels and lungs and even cause death. With the extensive use of these drugs by the human being particularly by the young men and women, the smuggling of these drugs has increased. Hence to stop the 
smuggling of these drugs, the security screening of passenger goods should be enhanced. Modern personal, parcel, vehicle and cargo inspection systems are non invasive imaging techniques based on the use of nuclear analytical techniques. The inspection systems are using penetrating radiations (neutrons. gamma and x-ray) in the scanning geometry with the detection of transmitted or radiation produced in the investigated sample.

The most common banned drugs are Heroin $(\mathrm{H})$, Cocaine $(\mathrm{CO})$, Caffeine (CA), Tetrahydrocannabinol (THC), Cannabinol (CBD), Tetrahydrocannabivarin (THCV) their molecular formulae are as shown in Table 1.

In the present work, the effective atomic number and electron densities have been calculated for some narcotic drugs for all photon interactions (coherent, incoherent, photoelectric, pair production and total photon interaction [with coherent]) in the energy range $1 \mathrm{KeV}-100 \mathrm{GeV}$. The variations of effective atomic number and electron density with energy are shown graphically for the all photon interactions. The variations of photon mass attenuation coefficient with energy is also shown graphically only for total photon interaction.

\section{The Method Of Computatio And Theoretical Basis}

A parallel beam of mono energetic X-ray or Gamma photons passing through matter is attenuated due to absorption and scattering. Attenuation due to absorption follows the Beer -Lambert's law,

$$
\mathrm{I}=\mathrm{I}_{\mathrm{o}} \mathrm{e}^{-\mu \mathrm{x}}=\mathrm{I}_{\mathrm{o}} \mathrm{e}^{-(\mu \rho) \mathrm{d}} \text {, }
$$

where $I_{o}$ and $I$ are the un-attenuated and attenuated photon intensities, $d$ is the mass per unit area $\left(\mathrm{g} / \mathrm{cm}^{2}\right)$ and $\mu / \rho$ is the photon mass attenuation coefficient $\left(\mathrm{cm}^{2} / \mathrm{g}\right)$. The photon mass attenuation coefficient $(\mu /$ $\rho)_{\mathrm{c}}$ for any chemical compound or mixture of elements is given by the 'mixture rule' [1]

$$
(\mu / \rho)_{\mathrm{c}}=\sum_{i} w_{i}(\mu / \rho)_{\mathrm{i}} \text {, }
$$

where $w_{i}$ and $(\mu / \rho)_{i}$ are the weight fraction and photon mass attenuation coefficient of the $i$ th constituent element, respectively. For a chemical compound the fraction by weight $\left(\mathrm{w}_{\mathrm{i}}\right)$ is given by; $w_{i}=\sum_{j}^{\frac{n_{i} A_{i}}{n_{j} A_{j}}}$, where $\mathrm{A}_{i}$ is the atomic weight of the $i$ th element and $n_{i}$ is the number of formula units.

The total cross- section $(\sigma)$ in turn can be related as the sum of partial cross sections,

$$
\sigma=\sigma_{\text {coh }}+\sigma_{\text {incoh }}+\tau+K+\sigma_{\text {ph, },},
$$

where $\sigma_{\text {coh }}, \sigma_{\text {incoh, }}$ are coherent (Rayleigh) and incoherent (Compton) scattering cross-sections, respectively. $\tau$ is the atomic photoelectric cross-section, $K$ is the positron electron pair production cross section and $\sigma_{\mathrm{ph}, \mathrm{n}}$ is the photonuclear cross -section .

The values of mass attenuation coefficient were then used to determine the total molecular crosssection $\left(\sigma_{\mathrm{m}}\right)$ by the following relation,

$$
\sigma_{\mathrm{m}}=\frac{M}{N_{A}}\left(\frac{\mu}{\rho}\right)_{c},
$$

where $\mathrm{M}=\sum_{i} n_{i} A_{i}$ is the molecular weight of the compound, $\mathrm{N}_{\mathrm{A}}$ is the Avogadro's number, $n_{i}$ is the total number of atoms (with respect to mass number) in the molecule, $\mathrm{A}_{i}$ is the atomic weight of $i$ th element in a molecule.

The effective (average) atomic cross-section $\left(\sigma_{a}\right)$ can easily be determined from the following equation,

$$
\sigma_{\mathrm{a}}=\frac{1}{N_{A}} \sum f_{i} A_{i}\left(\frac{\mu}{\rho}\right)_{i}
$$

Similarly, effective electronic cross- section $\left(\sigma_{\mathrm{e}}\right)$ for the individual element is given by the following formula,

$$
\sigma_{\mathrm{e}}=\frac{1}{N_{A}} \sum \frac{f_{i} A_{i}}{Z_{i}}\left(\frac{\mu}{\rho}\right)_{i}=\frac{\sigma_{a}}{Z_{\text {eff }}},
$$

where $f_{i}=n_{i} / \sum_{j} n_{j}$ and $\mathrm{Z}_{i}$ are the fractional abundance and atomic number of constituent element, respectively. $n_{i}$ is the total number of atoms of the constituent element, $\sum_{j} n_{j}$ is the total number of atoms present in the molecular formula.

Now, the effective atomic number $\left(\mathrm{Z}_{\mathrm{eff}}\right)$ can be given as $\mathrm{Z}_{\mathrm{eff}}=\frac{\sigma_{a}}{\sigma_{c}}$

The effective electron density, $\mathrm{N}_{\mathrm{el}}$ (number of electrons per unit mass) can be derived by using Eqs. (2) and (6),

$$
\mathrm{N}_{\mathrm{el}}=\frac{(\mu \mid \rho)_{c}}{\sigma_{c}}=\frac{N_{A}}{M} Z_{\text {eff }} \sum_{i} n_{i}
$$

Theoretical values for the mass attenuation coefficient can be found in the tabulation by Hubbell and Seltzer [25]. Instead of interpolating tabulated values and using the mixture rule, some computer programs such as WinXCom or its predecessor XCOM can save a lot of manual work and of course time. The XCOM program was originally developed by Berger and Hubbell [26] for calculating mass attenuation coefficients or photon interaction cross-section for any element, compound or mixture in the energy range $1 \mathrm{keV}-100 \mathrm{GeV}$. Latter this well-known and widely used program was enhanced and transformed to the Windows platform by Gerward et al. $[27,28]$ under the name WinXCom. All computations in the present work have been carried out using the program WinXCom. 


\section{Result And Discussion}

In the present work, the variations of $Z_{\mathrm{eff}}$ and $\mathrm{N}_{\mathrm{el}}$ with photon energy for narcotic drugs composed of different elements in different proportions (Table 1) were studied. The results are shown graphically in Figs. 213 for partial and total photon interaction processes. The $Z_{\text {eff }}$ and $N_{\mathrm{el}}$ values of are given in Table 2 only for total photon interaction. The present results clearly confirm the comment made by Hine [2] mentioned earlier that the effective atomic number varies with energy. In the following paragraphs energy dependence of $Z_{\mathrm{eff}}$ and $\mathrm{N}_{\mathrm{el}}$ for total and individual photon interactions are discussed.

\section{Total Photon Interaction (With Coherent)}

Fig. 1 shows the results of total mass attenuation coefficient of some narcotic drugs against photon energy. From figure it can be easily seen that (i) there are three energy ranges where photoelectric absorption, Compton scattering and pair production, respectively, are the dominating attenuation processes. It is seen that variation in $(\mu / \rho)_{c}$ with chemical composition is large below $100 \mathrm{keV}$ and significant between $0.1-30 \mathrm{MeV}$ and further there is negligible variation in $(\mu / \rho)_{c}$ above $30 \mathrm{MeV}$ photon energy. These variations are interpreted as being due to (i) photoelectric effect which varies as $\mathrm{Z}^{4-5}$ and (ii) less but significantly due to coherent scattering which varies as $\mathrm{Z}^{2-3}$. This fact has been verified experimentally by Singh [29] by measuring total mass attenuation coefficient of some soils. The present theoretical results are similar to the observations of Zavel'ski [30] who proposed a direct relation of $(\mu / \rho)$ with heavy metals in the rock salt at low energy. In the intermediate energy region, where incoherent scattering is the most dominant process, the mass attenuation coefficient is found to be constant and is due to the linear Z-dependence of incoherent scattering and insignificant role played by pair production. In the high energy region, the variation in mass attenuation coefficient is due to the $\mathrm{Z}^{2}$ dependence of pair production (30).

The variation of $Z_{\text {eff }}$ with photon energy for total photon interaction (Fig. 2) shows the dominance of different interaction process in different energy regions. The behaviour of all narcotic drugs listed is almost identical. In low energy region photoelectric interaction is dominant; $Z_{\text {eff }}$ varies as in case of photo interaction process. From $3-5 \mathrm{keV}$ onwards there is a sharp decrease in $Z_{\text {eff }}$ with energy up to $300 \mathrm{keV}$, showing that contribution of scattering processes increases which decreases $Z_{\text {eff. }}$. This fact is also confirmed by Sastry and Jayanand [3]. According to them Zeff of composite material for photoelectric interaction is greater than other processes.

From $300 \mathrm{keV}$ to $1.5 \mathrm{MeV}, \mathrm{Z}_{\mathrm{eff}}$ is almost independent of energy. This may be due to the dominance of incoherent scattering in this region. From 3 to $500 \mathrm{MeV}$, there is regular increase in $Z_{\text {eff }}$ with photon energy. This behaviour is due to mixed contribution of incoherent scattering and pair production. Above $500 \mathrm{MeV}, \mathrm{Z}_{\text {eff }}$ remains almost constant. This may be due to the dominance of pair production in the high energy region. It is observed that the variation in $Z_{\text {eff }}$ also depends upon relative proportion and the range of atomic numbers of the elements of which the narcotic drugs are composed.

\section{Photoelectric Absorption}

The variation of $Z_{\text {eff }}$ with photon energy for photoelectric absorption is shown in Fig. 3 which indicates that $Z_{\text {eff }}$ is almost independent of photon energy for all the narcotic drugs. From $1 \mathrm{keV}$ onwards $Z_{\text {eff }}$ increases sharply up to $4 \mathrm{MeV}$, and then it remains constant thereafter. This is due to the fact that photoelectric process is predominant at low energies $(<1 \mathrm{MeV})$ and for materials of higher atomic numbers than for low $\mathrm{Z}$ materials. Similar results were also obtained by Perumallu et al. [11] in multielement materials of biological importance and Manohara et al. [31] in essential amino acids. These results are in line with the results of Rama Rao et al. [4] and lingam et al. [10]. The variation in $\mathrm{Z}_{\mathrm{eff}}$ is almost independent of energy for all the narcotic drugs listed. It is due to the fact that the listed drugs have same elements and are of close atomic number.

\section{Incoherent (Compton) Scattering}

The variation of $Z_{\text {eff }}$ with photon energy for incoherent scattering is shown in Fig. 4 which indicates that $Z_{\text {eff }}$ increases sharply with increase in energy in the region $1-200 \mathrm{keV}$. Beyond $200 \mathrm{keV}, Z_{\text {eff }}$ is independent of photon energy for all. Most of the elements in a composite material have a value of Z/A of about 0.5 where as hydrogen has a value of 1.0, which effects Compton scattering. The present theoretical results are similar to the experimental findings of Parthasaradhi [9] who has reported the constancy of Compton $Z_{\text {eff }}$ in the energy range from 100 to $662 \mathrm{keV}$ for some alloys. Khayyoom and parthasarsdhi [9] have studied $Z_{\text {eff }}$ of some alloys; their experimental result suggests that in incoherent scattering $Z_{\text {eff }}$ is independent of photon energy from 20 to 800 $\mathrm{keV}$. In our study of , $Z_{\text {eff }}$ is independent of photon energy only above 1-200 keV but depends on photon energy below $150 \mathrm{keV}$. The variation of $Z_{\text {eff }}$ depends on respective proportion and the range of atomic numbers of the elements of which are composed. 


\section{Coherent (Rayleigh) Scattering.}

The variation of $Z_{\text {eff }}$ with photon energy for coherent scattering is shown in Fig. 5. From figure it is clear that $Z_{\text {eff }}$ increases with increase in energy from 1-100 keV (Heroin, Cocaine, THC, CBD), $1-150 \mathrm{keV}$ (Caffeine, THCV). From the upper limit onwards $Z_{\text {eff }}$ remains constant with increase in energy i.e. independent of energy. El-Kateb and Abdul Hamid [33] have shown that in materials containing carbon, hydrogen, oxygen the effective atomic number tends to be constant as a function of energy. Our results are in good agreement with their results at higher energy but differ slightly at lower energy.

\section{Pair Production (Nuclear Field)}

The variation of $Z_{\text {eff }}$ with photon energy for pair production in nuclear field is shown in Fig. 6, which shows that $Z_{\text {eff }}$ slightly decreases with increase in photon energy from 1.25 to $4000 \mathrm{MeV}$ and then it is almost independent of energy. It may be due to the fact that pair production in nuclear field is $\mathrm{Z}^{2}$ dependent.

\section{Pair Production (Electric Field)}

The variation of $Z_{\text {eff }}$ with photon energy for pair production in electric field is shown in Fig. 7. From figure it is clear that $Z_{\text {eff }}$ is independent of photon energy from $3 \mathrm{keV}$ to $\sim 60 \mathrm{MeV}$. From $60 \mathrm{MeV}$ onwards, $Z_{\text {eff }}$ decreases with increase of photon energy up to $15 \sim 60 \mathrm{GeV}$ and then it is independent of energy thereafter for all .

The variations of $\mathrm{N}_{\mathrm{el}}$ with photon energy in all the narcotic drugs for partial and total interaction processes are similar to that of $Z_{\text {eff }}$ and can be explained on the similar manner as that of $Z_{\text {eff }}$ and are shown in Figs.8-13.

\section{X. $\quad$ Figures And Tables}

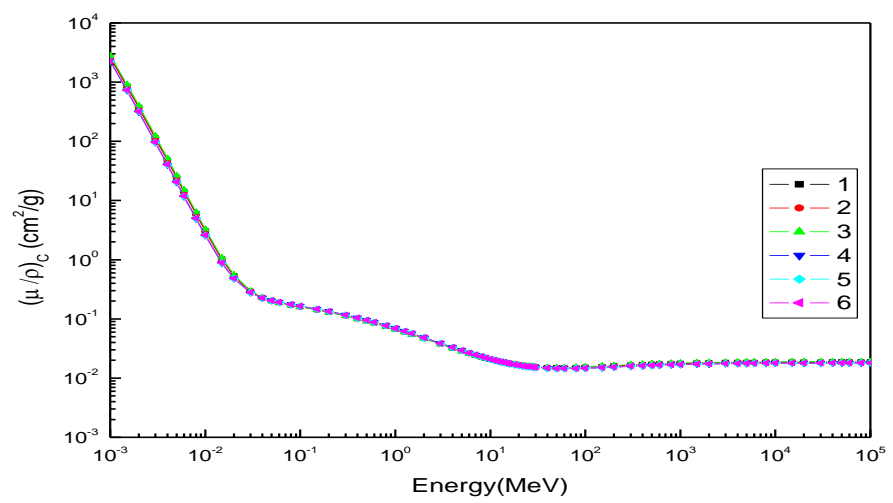

Fig. 1 Variation of photon mass attenuation coefficient $(\mu / \rho)_{\mathrm{c}}$ of narcotic drugs of Herion, $(\mathrm{H})$ Cocaine(CO),Caffeine(CA), Tetrahydrocannabinol (THC), Cannabinol (CBD), Tetrahydrocannabivarin (THCV)

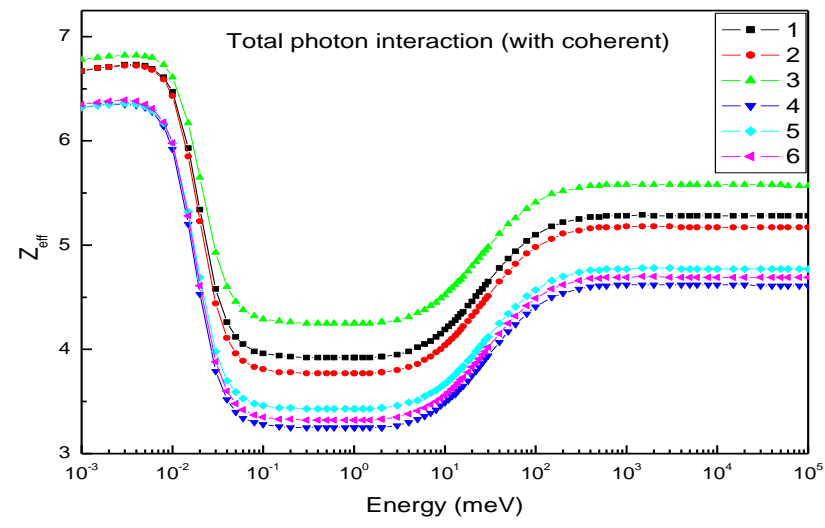

Fig.2 Variation of effective atomic number $Z_{\text {eff }}$ of Narcotic drugs with photon energy for total photon interaction (with coherent). 


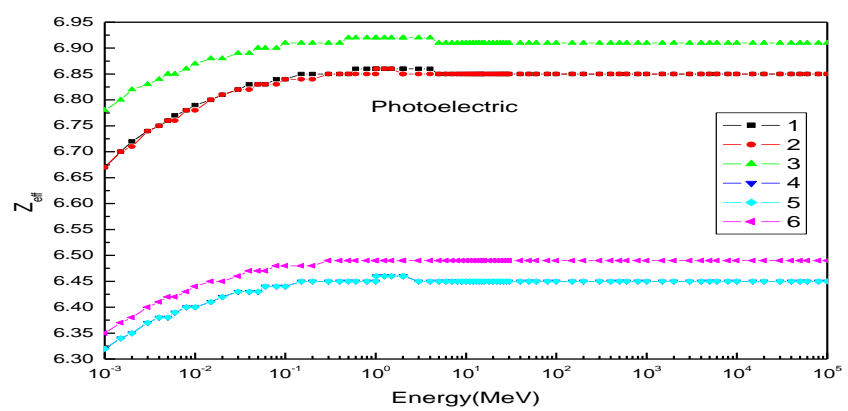

Fig. 3 Variation of effective atomic number $Z_{\text {eff }}$ of narcotic drugs with photon energy for photoelectric absorption.

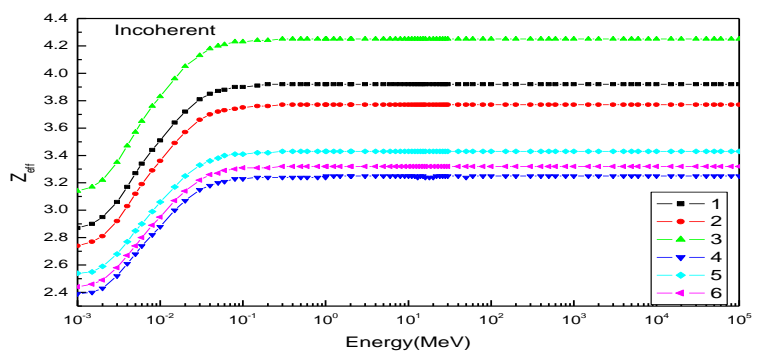

Fig. 4 Variation of effective atomic number $Z_{\text {eff }}$ of narcotic drugs with photon energy for incoherent scattering.

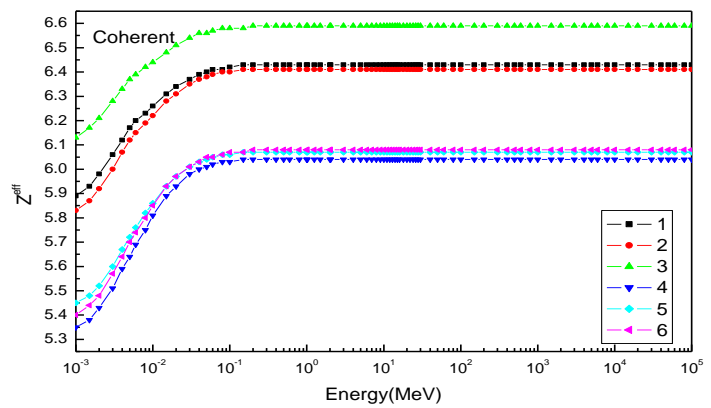

Fig. 5 Variation of effective atomic number $Z_{\text {eff }}$ of narcotic drugs with photon energy for coherent scattering.

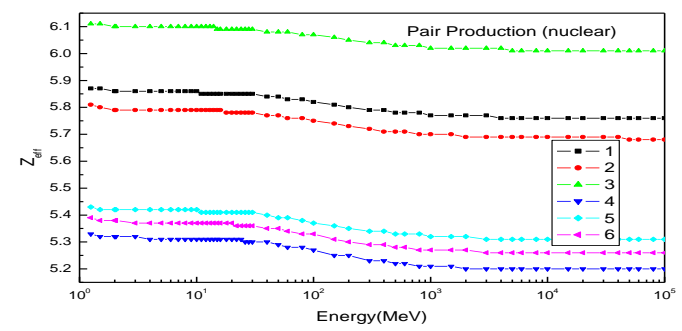

Fig. 6 Variation of effective atomic number $Z_{\text {eff }}$ of narcotic drugs with photon energy for pair production in nuclear field

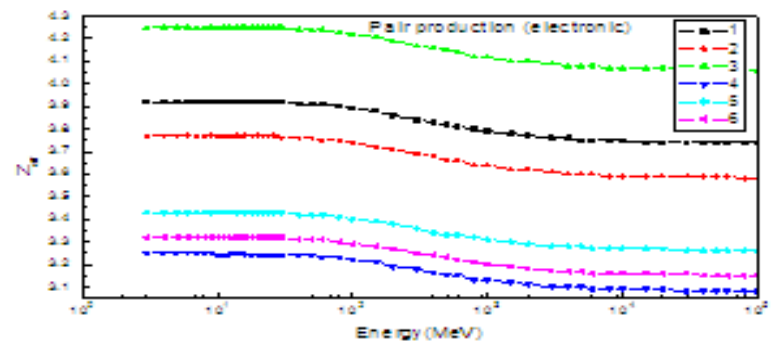

www.iosrjournals.org 


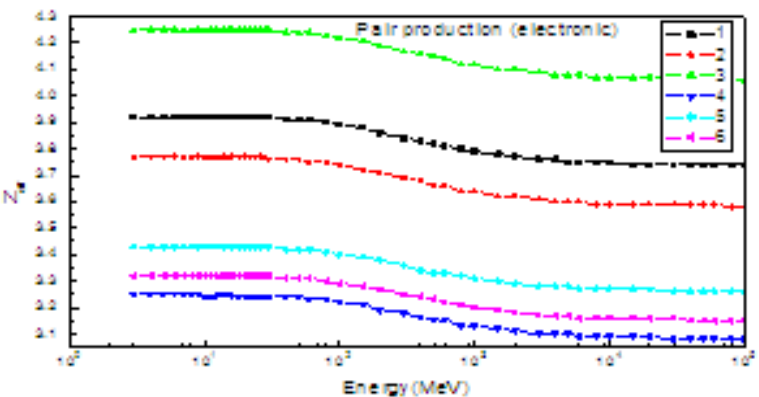

Fig. 7 Variation of effective atomic number Zeff of narcotic drugs with photon energy for pair production in electric field.

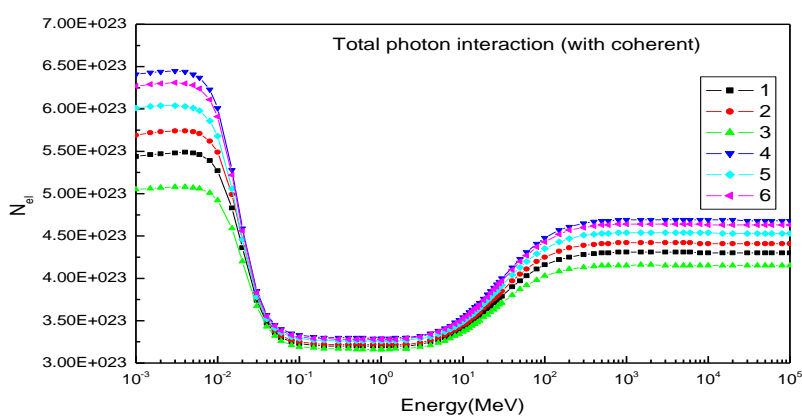

Fig. 8 Variation of effective electron density $\mathrm{N}_{\mathrm{el}}$ of narcotic drugs with photon energy for total photon interaction (with coherent).

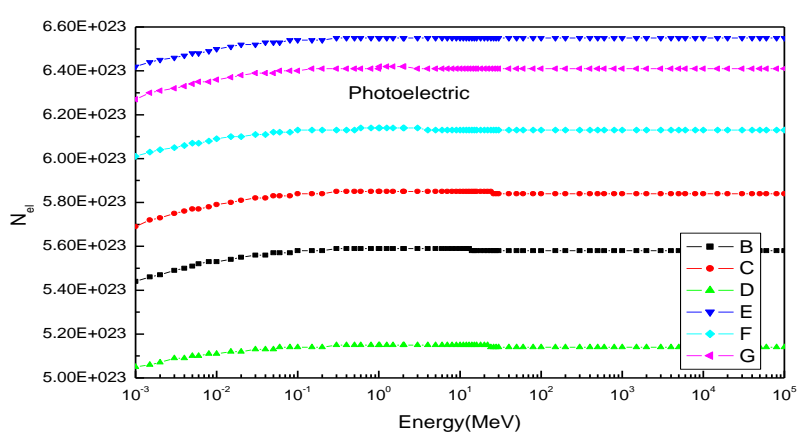

Fig. 9 Variation of effective electron density $\mathrm{N}_{\mathrm{el}}$ of narcotic drugs with photon energy for photoelectric absorption.

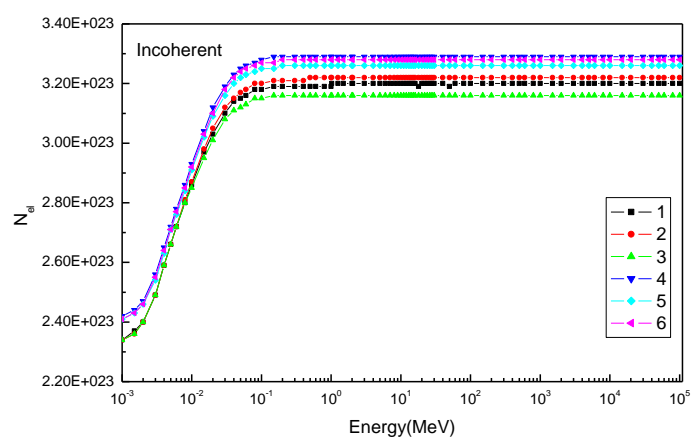

Fig. 10 Variation of effective electron density $\mathrm{N}_{\mathrm{el}}$ of narcotic drugs with photon energy for incoherent scattering. 


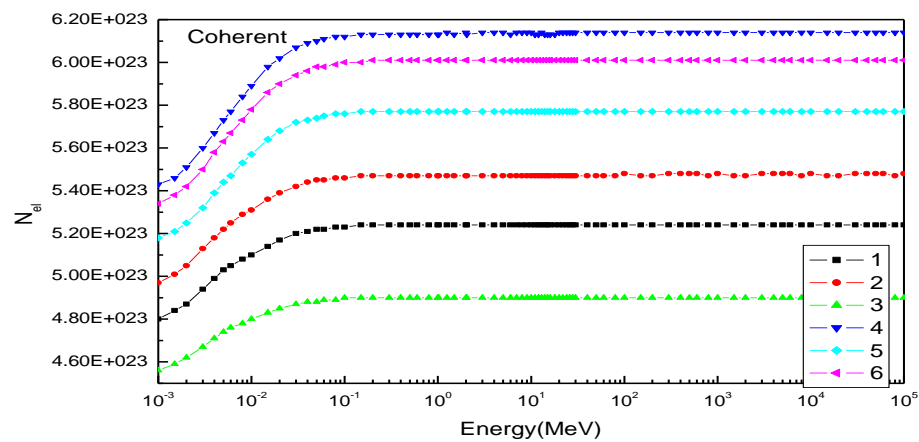

Fig. 11 Variation of effective electron density $\mathrm{N}_{\mathrm{el}}$ of narcotic drugs with photon energy for coherent scattering.

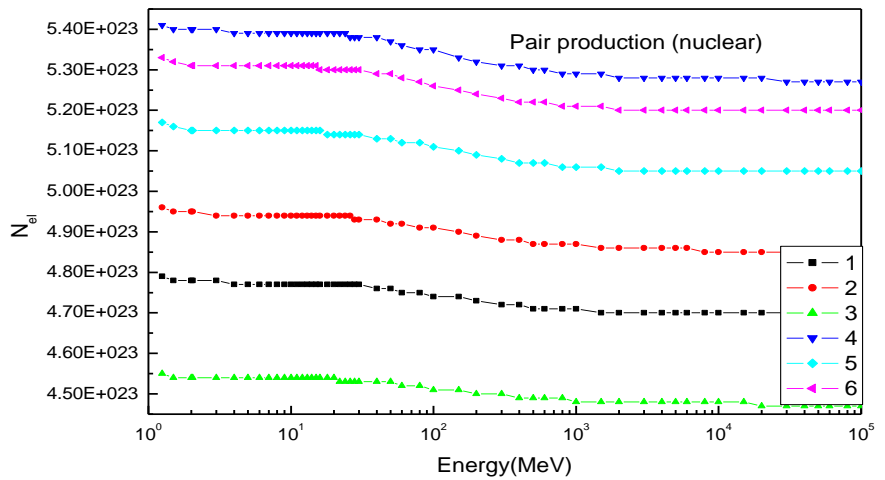

Fig. 12 Variation of effective electron density $\mathrm{N}_{\mathrm{el}}$ of narcotic drugs with photon energy for pair production in nuclear field.

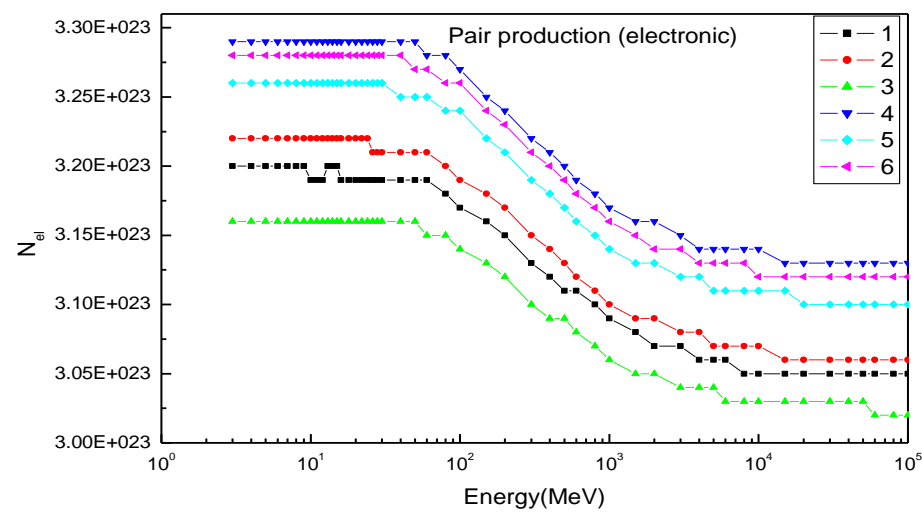

Fig. 13 Variation of effective electron density $\mathrm{N}_{\mathrm{el}}$ of Narcotic drugs with photon energy for pair production in electric field.

Table 1The molecular formula of some narcotic drugs.

\begin{tabular}{|l|l|l|}
\hline 1 & Heroin & $\mathrm{C}_{21} \mathrm{H}_{33} \mathrm{O}_{2} \mathrm{~N}$ \\
\hline 2 & Cocaine & $\mathrm{C}_{1} \mathrm{H}_{21} \mathrm{O}_{4} \mathrm{~N}$ \\
\hline 3 & Caffeine & $\mathrm{C}_{3} \mathrm{H}_{10} 0_{2} \mathrm{~N}_{4}$ \\
\hline 4 & Tetrahydrocannabinol(THC) & $\mathrm{C}_{21} \mathrm{H}_{30} \mathrm{O}_{2}$ \\
\hline 5 & Cannabinol (CBD) & $\mathrm{C}_{21} \mathrm{H}_{36} \mathrm{O}_{2}$ \\
\hline 6 & Tetrahydrocannabivarin (THCV) & $\mathrm{C}_{19} \mathrm{H}_{18} \mathrm{O}_{2}$ \\
\hline
\end{tabular}


Studies on Mass Attenuation Coefficient, Effective Atomic Numbers and Electron Densities of Some

Table 2Effective atomic numbers (zeff) and effective electron density (NelX1023 electrons /g) of narcotic drugs (listed in table 1) for total photon interaction (with coherent)

\begin{tabular}{|c|c|c|c|c|c|c|c|c|c|c|c|c|}
\hline \multirow[b]{3}{*}{ ENERGY } & \multicolumn{6}{|c|}{ EFFECTIVE ATONIC NUMBER (Z,E) } & \multicolumn{6}{|c|}{ Effectiva alectron density $\left(\mathrm{N}_{0} \mathrm{X} 10^{2+}\right)$} \\
\hline & HERON & COCAINE & CAFFENE & THC & CBD & $\mathrm{THCV}$ & HERON & COCANE & CAFFENE & THC & $C B D$ & $\mathrm{THCV}$ \\
\hline & Zist & Zist & Zist & Zist & Zist & $z_{\text {zat }}$ & $N_{L}$ & $N_{L}$ & $\mathbb{N}_{t}$ & $\mathbb{N}_{t_{i}}$ & $N_{i}$ & $N_{i}$ \\
\hline $1.00 \mathrm{E}-03$ & 6.67 & 6.67 & 6.78 & 6.32 & 6.32 & 635 & 5.44 & 569 & 505 & $\frac{m i}{6.41}$ & 601 & 6.27 \\
\hline $1.50 \mathrm{E}-03$ & 6.7 & 6.7 & 6.8 & 634 & 634 & 637 & 5.46 & 5.72 & 506 & 6.43 & 6.03 & 629 \\
\hline $200 \mathrm{E}-03$ & 6.71 & 6.71 & 6.81 & 635 & 635 & 638 & 5.47 & 5.73 & 5.07 & 6.44 & 6.04 & 630 \\
\hline $3.00 \mathrm{E}-03$ & 6.73 & 6.72 & 6.82 & 635 & 636 & 639 & 5.48 & 5.74 & 5.08 & 6.45 & 6.04 & 631 \\
\hline $400 \mathrm{E}-03$ & 673 & 6.72 & 682 & 634 & 635 & 638 & 549 & 5.74 & 508 & 644 & 603 & 630 \\
\hline $5.00 \mathrm{E}-03$ & 6.72 & 6.71 & 6.81 & 632 & 6.33 & 635 & 5.48 & 5.73 & 5.07 & 6.41 & 6.01 & 628 \\
\hline $6.00 \mathrm{E}-03$ & 6.69 & 6.68 & 6.8 & 628 & 629 & 631 & 5.46 & 5.71 & 5.06 & 637 & 598 & 6.24 \\
\hline $8.00 \mathrm{E}-03$ & 6.61 & 6.59 & 6.73 & 6.14 & 6.17 & 6.18 & 539 & 5.62 & 5.01 & 623 & 5.86 & 6.11 \\
\hline $1.00 \mathrm{E}-02$ & 6.47 & 6.43 & 6.61 & 592 & 598 & 598 & 527 & 549 & 492 & 601 & 5.68 & 591 \\
\hline $150 \mathrm{E}-02$ & 593 & 5.85 & 6.17 & 52 & 532 & 528 & 483 & 499 & 459 & 528 & 5.06 & 5.22 \\
\hline $200 \mathrm{E}-02$ & 534 & 5.23 & 5.65 & 453 & 469 & 461 & 436 & 446 & 420 & 459 & 446 & 456 \\
\hline $3.00 \mathrm{E}-02$ & 458 & 444 & 493 & 3.79 & 398 & 388 & 3.74 & 3.79 & 3.67 & 3.85 & 3.78 & 3.83 \\
\hline $400 \mathrm{E} \cdot 02$ & 426 & 4.11 & 46 & 352 & 3.7 & 36 & 3.47 & 351 & 3.43 & 357 & 352 & 355 \\
\hline $500 \mathrm{E} \cdot 02$ & 412 & 396 & 446 & 34 & 359 & 348 & 336 & 338 & 332 & 345 & 341 & 344 \\
\hline $6.00 \mathrm{E}-02$ & 405 & 3.89 & 438 & 334 & 353 & 342 & 330 & 332 & 326 & 340 & 336 & 338 \\
\hline $8.00 \mathrm{E}-02$ & 398 & 3.83 & 432 & 33 & 3.48 & 337 & 325 & 327 & 321 & 335 & 331 & 333 \\
\hline $1.00 \mathrm{E}-01$ & 3.96 & 3.81 & 429 & 328 & 3.46 & 335 & 323 & 325 & 3.19 & 333 & 329 & 331 \\
\hline $150 \mathrm{E}-01$ & 3.94 & 3.78 & 427 & 326 & 3.44 & 333 & 321 & 323 & 3.18 & 331 & 327 & 329 \\
\hline $200 \mathrm{E} \cdot 01$ & 393 & 3.78 & 426 & 325 & 3.44 & 333 & 320 & 322 & 3.17 & 330 & 327 & 329 \\
\hline $300 \mathrm{E}-01$ & 392 & 3.77 & 425 & 325 & 3.43 & 332 & 320 & 322 & 3.17 & 330 & 326 & 328 \\
\hline $400 \mathrm{E}-01$ & 392 & 3.77 & 425 & 325 & 343 & 332 & 320 & 322 & 3.17 & 330 & 326 & 328 \\
\hline $500 \mathrm{E} \cdot 01$ & 392 & 3.77 & 425 & 325 & 343 & 332 & 320 & 322 & 3.16 & 330 & 326 & 328 \\
\hline $600 \mathrm{E} \cdot 01$ & 392 & 3.77 & 425 & 325 & 343 & 332 & 320 & 322 & 3.16 & 330 & 326 & 3.28 \\
\hline $800 \mathrm{E} \cdot 01$ & 392 & 3.77 & 425 & 325 & 3.43 & 332 & 320 & 322 & 3.16 & 329 & 326 & 328 \\
\hline $1.00 \mathrm{E}+00$ & 3.92 & 3.77 & 425 & 325 & 3.43 & 332 & 320 & 322 & 3.16 & 329 & 326 & 328 \\
\hline $1.02 \mathrm{E}+00$ & 392 & 3.77 & 425 & 325 & 3.43 & 332 & 320 & 322 & 3.16 & 329 & 326 & 328 \\
\hline $1.25 \mathrm{E}+00$ & 392 & 3.77 & 425 & 325 & 343 & 332 & 320 & 322 & 3.16 & 329 & 326 & 328 \\
\hline $150 \mathrm{E}+00$ & 3.92 & 3.77 & 425 & 325 & 3.43 & 332 & 320 & 322 & 3.17 & 330 & 326 & 328 \\
\hline $200 \mathrm{E}+00$ & 393 & 3.78 & 426 & 325 & 3.44 & 3.33 & 320 & 322 & 3.17 & 330 & 327 & 329 \\
\hline $204 E+00$ & 393 & 3.78 & 426 & 325 & 3.44 & 333 & 320 & 322 & 3.17 & 330 & 327 & 329 \\
\hline $3.00 \mathrm{E}+00$ & 395 & 3.8 & 428 & 3.27 & 3.46 & 335 & 322 & 3.24 & 3.19 & 332 & 329 & 331 \\
\hline $400 \mathrm{E}+00$ & 398 & 383 & 431 & 33 & 349 & 338 & 325 & 327 & 321 & 335 & 331 & 334 \\
\hline $5.00 \mathrm{E}+00$ & 402 & 3.86 & 435 & 333 & 351 & 3.41 & 327 & 330 & 3.24 & 338 & 334 & 337 \\
\hline $600 \mathrm{E}+00$ & 405 & 39 & 438 & 336 & 355 & 344 & 330 & 333 & 326 & 341 & 337 & 340 \\
\hline $7.00 \mathrm{E}+00$ & 408 & 393 & 442 & 339 & 3.58 & 347 & 333 & 336 & 329 & 3.44 & 3.40 & 343 \\
\hline $800 \mathrm{E}+00$ & 412 & 397 & 445 & 342 & 361 & 35 & 336 & 339 & 332 & 3.48 & 343 & 3.46 \\
\hline $900 \mathrm{~B}+00$ & 4.15 & 4 & 449 & 346 & 3.64 & 353 & 339 & 342 & 334 & 351 & 346 & 349 \\
\hline $100 \mathrm{E}+01$ & 419 & 404 & 452 & 349 & 367 & 356 & 341 & 345 & 337 & 354 & 349 & 352 \\
\hline $1.10 \mathrm{~B}+01$ & 422 & 407 & 456 & 352 & 3.7 & 359 & 3.44 & 347 & 339 & 357 & 352 & 355 \\
\hline $120 \mathrm{E}+01$ & 425 & 4.1 & 459 & 355 & 3.73 & 3.62 & 3.46 & 3.50 & 341 & 3.60 & 355 & 358 \\
\hline $130 \mathrm{E}+01$ & 428 & 4.13 & 462 & 357 & 3.76 & 3.65 & 3.49 & 353 & 3.44 & 3.63 & 357 & 3.61 \\
\hline $140 \mathrm{E}+01$ & 431 & 4.16 & 465 & 36 & 3.79 & 3.68 & 351 & 3.55 & 3.46 & 3.66 & 3.60 & 3.64 \\
\hline $150 \mathrm{E}+01$ & 434 & 4.19 & 467 & 3.63 & 381 & 3.71 & 3.54 & 358 & 3.48 & 3.68 & 3.63 & 3.66 \\
\hline $1.60 \mathrm{E}+01$ & 436 & 422 & 47 & 3.65 & 3.84 & 3.73 & 3.56 & 3.60 & 350 & 3.71 & 3.65 & 3.69 \\
\hline $1.80 \mathrm{E}+01$ & 442 & 427 & 475 & 3.7 & 3.89 & 3.78 & 3.60 & 3.65 & 354 & 3.76 & 3.70 & 3.74 \\
\hline $200 \mathrm{E}+01$ & 446 & 432 & 48 & 3.75 & 393 & 383 & 3.64 & 369 & 357 & 381 & 3.74 & 3.78 \\
\hline $220 \mathrm{~B}+01$ & 451 & 436 & 484 & 3.79 & 398 & 387 & 367 & 3.73 & 360 & 385 & 378 & 383 \\
\hline $240 \mathrm{E}+01$ & 455 & 441 & 488 & 383 & 402 & 391 & 3.71 & 3.76 & 363 & 389 & 382 & 387 \\
\hline $260 \mathrm{~B}+01$ & 458 & 444 & 492 & 387 & 405 & 395 & 3.74 & 3.79 & 3.66 & 393 & 385 & 390 \\
\hline $280 \mathrm{E}+01$ & 462 & 448 & 495 & 391 & 409 & 398 & 3.77 & 3.82 & 369 & 396 & 389 & 394 \\
\hline $3.00 \mathrm{E}+01$ & 465 & 451 & 498 & 394 & 4.12 & 402 & 3.79 & 3.85 & 3.71 & 400 & 392 & 397 \\
\hline $400 \mathrm{~B}+01$ & 4.78 & 465 & 5.11 & 407 & 425 & 4.15 & 390 & 397 & 380 & 4.13 & 404 & 4.10 \\
\hline $500 \mathrm{E}+01$ & 487 & 4.74 & 52 & 4.17 & 434 & 425 & 397 & 405 & 387 & 423 & 4.13 & 420 \\
\hline $600 \mathrm{~B}+01$ & 494 & 482 & 526 & 424 & 441 & 432 & 403 & 4.11 & 392 & 431 & 420 & 427 \\
\hline $8.00 \mathrm{E}+01$ & 504 & 492 & 535 & 434 & 451 & 442 & 4.11 & 420 & 398 & 441 & 429 & 437 \\
\hline $100 \mathrm{E}+02$ & 5.1 & 498 & 5.41 & 441 & 457 & 449 & 4.16 & 425 & 403 & 4.48 & 435 & 443 \\
\hline $1.50 \mathrm{Z}+02$ & 5.18 & 5.06 & 549 & 45 & 4.66 & 458 & 422 & 432 & 408 & 457 & 443 & 452 \\
\hline $200 \mathrm{E}+02$ & 522 & 511 & 552 & 454 & 47 & 462 & 425 & 436 & 411 & 461 & 447 & 457 \\
\hline $300 \mathrm{E}+02$ & 525 & 5.14 & 555 & 458 & 474 & 466 & 428 & 439 & 413 & 465 & 451 & 460 \\
\hline $400 \mathrm{E}+02$ & 527 & 5.16 & 557 & 46 & 476 & 468 & 429 & 440 & 4.14 & 467 & 452 & 462 \\
\hline
\end{tabular}




\begin{tabular}{|c|c|c|c|c|c|c|c|c|c|c|c|c|}
\hline $500 \mathrm{E}+02$ & 527 & 517 & 557 & 461 & 4.76 & 468 & 430 & 4.41 & 415 & 468 & 453 & 4.63 \\
\hline $600 \mathrm{E}+02$ & 528 & 517 & 558 & 461 & 4.77 & 469 & 430 & 441 & 415 & 468 & 453 & 463 \\
\hline $8.00 E+02$ & 528 & 5.17 & 558 & 462 & 4.77 & 469 & 431 & 4.42 & 415 & 469 & 454 & 4.64 \\
\hline $1.00 E+03$ & 528 & 5.18 & 558 & 4.62 & 4.77 & 469 & 431 & 4.42 & 4.15 & 469 & 454 & 4.64 \\
\hline $150 \mathrm{E}+03$ & 529 & 5.18 & 558 & 462 & 4.78 & 4.7 & 431 & 442 & 416 & 469 & 454 & 4.64 \\
\hline $200 E+03$ & 528 & 5.18 & 558 & 4.62 & 4.78 & 4.7 & 431 & 4.42 & 4.16 & 469 & 454 & 4.64 \\
\hline $3.00 E+03$ & 528 & 5.18 & 558 & 4.62 & 4.78 & 469 & 431 & 4.42 & 4.15 & 469 & 454 & 4.64 \\
\hline $400 E+03$ & 528 & 5.17 & 558 & 4.62 & 4.77 & 469 & 431 & 4.42 & 4.15 & 469 & 454 & 4.64 \\
\hline $500 \mathrm{E}+03$ & 528 & 5.17 & 558 & 462 & 4.77 & 469 & 431 & 442 & 415 & 469 & 454 & 4.64 \\
\hline $6.00 \mathrm{E}+03$ & 528 & 5.17 & 558 & 462 & 4.77 & 469 & 431 & 442 & 415 & 469 & 454 & 4.64 \\
\hline $8.00 E+03$ & 528 & 5.17 & 558 & 4.62 & 4.77 & 469 & 430 & 4.41 & 4.15 & 469 & 454 & 4.64 \\
\hline $1.00 \mathrm{E}+04$ & 528 & 5.17 & 558 & 4.62 & 477 & 469 & 430 & 4.41 & 4.15 & 469 & 454 & 4.63 \\
\hline $1.50 \mathrm{E}+04$ & 528 & 5.17 & 558 & 4.62 & 4.77 & 469 & 430 & 441 & 4.15 & 469 & 453 & 4.63 \\
\hline $200 E+04$ & 528 & 5.17 & 558 & 462 & 4.77 & 469 & 430 & 441 & 415 & 469 & 453 & 4.63 \\
\hline $3.00 E+04$ & 528 & 5.17 & 558 & 4.61 & 4.77 & 469 & 430 & 4.41 & 4.15 & 4.68 & 453 & 4.63 \\
\hline $400 E+04$ & 528 & 5.17 & 558 & 4.61 & 4.77 & 469 & 430 & 4.41 & 4.15 & 4.68 & 453 & 4.63 \\
\hline $5.00 \mathrm{E}+04$ & 528 & 5.17 & 558 & 4.61 & 4.77 & 469 & 430 & 4.41 & 4.15 & 4.68 & 453 & 4.63 \\
\hline $6.00 E+04$ & 528 & 5.17 & 557 & 461 & 4.77 & 469 & 430 & 441 & 4.15 & 468 & 453 & 4.63 \\
\hline $8.00 E+04$ & 528 & 5.17 & 557 & 4.61 & 4.77 & 4.69 & 430 & 4.41 & 4.15 & 4.68 & 453 & 4.63 \\
\hline $1.00 \mathrm{E}+05$ & 528 & 5.17 & 557 & 461 & 4.77 & 469 & 430 & 4.41 & 4.15 & 468 & 453 & 4.63 \\
\hline
\end{tabular}

\section{Conclusion}

We reported a new data on $Z_{\text {eff }}$ and $N_{\text {el }}$ in the wide energy region $1 \mathrm{KeV}-100 \mathrm{GeV}$ for the well known narcotic drugs. These data are expected to be useful in the field of medical diagnostic. Also to the best of the knowledge of authors, these data are the first in its kind estimated for the wide energy range.

\section{References}

[1] D.F. Jackson, D.J. Hawkes, Phys. Rep. 70 (1981) 169

[2] G.J. Hine, Phys. Rev. 85 (1952) 725.

[3] K.S.R. Sastry, S. Jnanananda, J. Sci. Ind. Res. 17B (1958) 389.

[4] J. Rama Rao, V. Lakshminarayana, S. Jnanananda, J. Sci. Ind. Res.20B (1961) 597

[5] J. Rama Rao, V. Lakshminarayana, S. Jnanananda, Indian J. PureAppl. Phys. 1 (1963) 375.

[6] R.C. Murthy, Nature (London) 207 (1965) 398.

[7] K. Parthasaradhi, Indian J. Pure Appl. Phys. 6 (1968) 609

[8] Visweswara Rao, K. Parthasaradhi, Indian J. Pure Appl. Phys. 6(1968) 643. Khayyoom, K. Parthasaradhi, Indian J. Pure Appl. Phys. 8 (1970)845.

[9] S.C. Lingam, K.S. Babu, D.V.K. Reddy, Indian J. Phys. 53A (1984)285. Perumallu, A.S.Nageswara Rao, G.Krishna Rao, Physica 132C (1985) 388.

[10] Ah El - Kateb, R.A.M. Rizk, A. M. Abdul - Kader, Ann. Nucl.Energy 27 (2000) 1333

[11] N. Govinda Nayak, M.G. Vijaya, K. Siddappa, Radiat. Phys. Chem.61 (2001) 559.

[12] Shivalinge Gowda, S. Krishnaveni, T. Yashoda, T.K. Umesh, Ramakrishna Gowda, PRAMANA-J. Phys. 63 (2004) 529.

[13] Orhan, E. Salih, J. Quant. Spectrosc. Rad. Trans. 85 (2004) 115.

[14] Orhan, E. Salih, H.K. Ismail, C. Guven, J. Quant. Spectrosc. Rad.Trans. 91 (2005) 485

[15] U. Cevik, H. Baltas, S. Celik, I. Karaca, A.I. Kopya, Supercond. Sci.Technol. 18 (2005) 101. Ugur, B. Hasan, C. Ahmet, B. Emin, Nucl. Instr. and Meth. B 247(2006) 173.

[16] H. Baltas, S. Celika, U. Cevik, E. Yanmazb, Radiat. Measur. 42(2007) 55.

[17] S.S. Hiremath, G.C. Chikkur, Indian J. Pure Appl. Phys. 31 (1993)855.

[18] V. Manjunathaguru, T.K. Umesh, J. Phys. B: At. Mol. Opt. Phys. 39(2006) 3969.

[19] Pravina P Pawar and Govind K Bichile journal of chem..and Pharma.Research 2012, 4(1):59-66

[20] Q. Lu, Ph.D thesis, Virginia Polytechnic Institute and State University, Blacksburg, Virginia,1999.

[21] Chemical and Biological Medical Treatment Symposium - Industry II World Congress on Chemical and Biological Terrorism

[22] J.H. Hubbell, S.M. Seltzer, Report, NISTIR-5632 (1995).

[23] M.J. Berger, J.H. Hubbell, Report, NBSIR 87-3597 (1987/1999).XCOM: Photon cross-sections database, Web Version 1.2. <http://physics.nist.gov/xcom>. Originally published as XCOM: Photon Cross-Section on a Personal computer.

[24] L. Gerward, N. Guilbert, K.B. Jensen, H. Levring, Radiat. Phys.Chem. 60 (2001) 23.

[25] L. Gerward, N. Guilbert, K.B. Jensen, H. Levring, Radiat. Phys.Chem. 71 (2004) 653

[26] M. Singh, Ph.d. thesis, Pbi. Univ. Patiala, India (1992)

[27] F.S. Zavel'skii, Atom. Energy 16 (1964) 266.

[28] S.R.Manohara et al. Nucl.Instr.and Meth.in phys. Res. B 258 (2007) 321-328.

[29] G.S. Mudahar, M. Singh, G. Singh, Appl. Radiat. Isot. 42 (1991) 509.

[30] A.H. El-Kateb, A.S. Abdul Hamid, Radiat. Isot. 42 (1991) 303. 